\title{
Políticas curriculares, ensino médio e os paradoxos da democracia: traços conceituais para a composição de um diagnóstico crítico
}

Curriculum policies, high school and the democracy paradoxes: conceptual perspectives for the composition of a critical diagnosis Políticas curriculares, escuela secundaria y paradojas de la democracia: rasgos conceptuales para la composición de un diagnóstico crítico

ROBERTO RAFAEL DIAS DA SILVA

http://orcid.org/0000-0001-6927-3435

Universidade do Vale do Rio dos Sinos

Programa de Pós-Graduação em Educação

Departamento de Educação

São Leopoldo, RS, Brasil

LUTHIANE MISZAK VALENÇA DE OLIVEIRA

https://orcid.org/0000-0001-5619-9029

Universidade do Vale do Rio dos Sinos

Programa de Pós-Graduação em Educação

Departamento de Educação

São Leopoldo, RS, Brasil

\begin{abstract}
Resumo: $\mathrm{O}$ artigo buscará delinear alguns traços conceituais para a composição de um diagnóstico crítico enfatizando o declínio dos níveis de confiança sobre a política e as instituições democráticas, considerando os atuais paradoxos da democracia, o debate sobre a qualidade e o direito de aprendizagem na interface com as racionalidades políticas orientadoras da implementação de currículos para o Ensino Médio no Brasil. Inscrito na tradição dos Estudos Curriculares, suas análises se derivam de uma pesquisa documental dos textos curriculares publicados na última década. Destaca-se que o artigo se posiciona na defesa de políticas curriculares ancoradas nas possibilidades de uma governança escolar democrática que revitalizem procedimentos de escuta e negociação permanente com os atores escolares, sobretudo com as juventudes contemporâneas.
\end{abstract}

Palavras-chave: Política curricular. Qualidade. Direito à Educação. Ensino Médio. 


\begin{abstract}
Considering the current paradoxes of democracy, the debate on the quality and the right to learn in the interface with the political rationalities that guide the implementation of the study plans for secondary school in Brazil, the article will seek to outline some conceptual features for the composition of a diagnosis, with emphasis on decreasing levels of trust in democratic policies and institutions. Their analyses are derived from a documentary investigation of the curricular texts published in the last decade from the Curricular Studies. It is noteworthy that the article defends curricular policies anchored in the possibilities of democratic school governance that revitalize the procedures of listening and permanent negotiation with school actors, especially with contemporary youth.
\end{abstract}

Keywords: Curricular policy. Quality. Education rights. High school.

Resumen: Considerando las paradojas actuales de la democracia, el debate sobre la calidady el derecho a aprender en la interfaz, con las racionalidades politicas que guian la implementación de los planes de estudio para la escuela secundaria en Brasil, el articulo buscará bosquejar algunos rasgos conceptuales para la composición de un diagnóstico con énfasis en la disminución de los niveles de confianza en las politicas y las instituciones democráticas. A partir de los Estudios Curriculares, sus análisis se derivan de una investigación documental de los textos curriculares publicados en la última década. El artículo se posiciona en la defensa de políticas curriculares ancladas en las posibilidades de la gobernanza escolar democrática que revitalicen los procedimientos de escucha y negociación permanente con los actores escolares, especialmente con la juventud contemporánea.

Palabras clave: Política curricular. Calidad. Derecho a la educación. Escuela secundaria.

\title{
INTRODUÇÃO
}

Deveríamos admitir que as instituições democráticas estão se tornando marginais exatamente no momento em que a democracia parece experimentar crescente sucesso? (GIDDENS, 2000, p. 83).

Em obra publicada na virada para o século XXI, o sociólogo Anthony Giddens buscava captar alguns sentimentos que as pessoas estavam experimentando na virada do século no que tange à globalização, aos riscos, à família, à tradição e à democracia. Derivado das Conferências Reitch, da BBC, a obra "Mundo em descontrole: o que a globalização está fazendo de nós" trata de uma leitura incontornável acerca da sociedade e dos modos de vida que experimentávamos naquele período. Para fins deste texto e tal como esboçado em nossa epígrafe, desde um prisma curricular, interessa-nos neste momento interrogar os sentidos de democracia e de educação democrática em nosso tempo. Mais que isso, desejamos ingressar no importante debate acerca das políticas curriculares democráticas.

A partir da segunda metade do século XX, gradativamente, deparamonos com uma possível "visão triunfalista" da democracia, em articulação aos livres mercados. Encontramos ondas de democratização em variados continentes, como 
a América Latina por exemplo, e um processo de consolidação destes processos nos Estados Unidos e na Europa. Giddens (2000) sugere que, após a década de 1970, "a democracia se estendeu a mais de trinta novos países, enquanto todos os estados democráticos existentes conservaram suas instituições democráticas" (p. 80). Ainda que o sociólogo defenda a democracia como o melhor sistema, interessa-nos fazer uso de um diagnóstico bastante preciso que perpassa sua argumentação, qual seja: o advento do "paradoxo da democracia" (p. 81).

Os níveis de confiança sobre a política e as instituições democráticas caem drasticamente, sobretudo entre os mais jovens, na medida em que os processos democráticos se generalizam. Interroga Giddens, de modo perspicaz: "Por que os cidadãos de países democráticos estão ficando visivelmente desiludidos com o governo democrático, ao mesmo tempo em que este se espalha por todo o resto do mundo?" (2000, p. 81). Em termos educacionais, o paradoxo da democracia supõe, por um lado, a compreensão da emergência de grupos conservadores disputando território com os modelos de educação democrática e, por outro, a necessidade de uma "democratização da democracia" (p. 84).

Transcorridas duas décadas do pressentimento manifestado no texto de Giddens, os cenários contemporâneos efetivamente avançaram para contestações variadas acerca das formas democráticas. No contexto brasileiro, foco analítico de nosso estudo, o processo de impedimento da presidente Dilma Rousseff, acompanhado da posterior eleição do extremista Jair Bolsonaro, colocou-nos diante de uma ascensão crescente de movimentos de tendência neoconservadora no âmbito das políticas, em geral, e das políticas curriculares, de modo específico. $\mathrm{Na}$ literatura internacional, pesquisadores como Michael Apple (2016), Stephen Ball (2016) e António Viñao (2016) têm delineado bons diagnósticos acerca deste contexto nas políticas educacionais.

Especificamente, neste artigo, analisando as condições brasileiras, examinaremos as racionalidades políticas orientadoras dos atuais regimes de implementação das políticas curriculares para o Ensino Médio. O estudo buscará delinear alguns traços conceituais para a composição de um diagnóstico crítico; enfatizando, principalmente, o declínio dos níveis de confiança sobre a política e as instituições democráticas, considerando os atuais paradoxos da democracia, amplamente descritos nas teorizações sociais contemporâneas. Os novos contornos do debate acerca dos direitos de aprendizagem, associado à intensificação da lógica meritocrática em torno da qualidade, serão os eixos estruturantes da analítica desenvolvida.

O texto inscreve-se na tradição dos Estudos Curriculares e, do ponto de vista metodológico, vale a pena destacar que suas análises se derivam de uma pesquisa documental dos textos curriculares publicados pelo Estado brasileiro no 
decorrer da última década. Ao final das três seções que o constituem, o artigo se posiciona na defesa de políticas curriculares ancoradas nas possibilidades de uma governança escolar democrática, capaz de revitalizar os processos de seleção e organização do conhecimento escolar por meio de procedimentos de escuta e negociação permanente com os atores escolares, sobretudo com as juventudes contemporâneas.

\section{SOBRE O PARADOXO DA DEMOCRACIA: BREVES ANOTAÇÕES}

O pressentimento de Giddens (2000) acerca de um paradoxo da democracia também foi encontrado nas teorizações sociais contemporâneas, em autores como Brown (2016), Bauman (2016) e Laval e Dardot (2017). A cientista política Wendy Brown (2016), em seus escritos recentes, tem sinalizado os modos pelos quais o neoliberalismo tem silenciosamente operado para converter a democracia em termos econômicos. Delineia-se, em sua percepção, uma "demolição conceitual de democracia" (p. 5), com seu triunfo mundial após o final da Guerra Fria. Seu diagnóstico nos conduz a repensar a perspectiva de que a democracia havia se constituído como uma conquista permanente em países ocidentais.

Reconhecendo que expressões como "democracia" e "neoliberalismo" apresentam múltiplos significados, a cientista estadunidense sinaliza - em termos platônicos - para uma nova relação entre as cidades e as pessoas.

O mais surpreendente desta nova homologia entre a cidade e a alma é que suas coordenadas são econômicas e não políticas. Uma vez que o indivíduo e o Estado se convertem em projetos gerenciais, mais que de governo, e que um marco econômico e fins do mesmo tipo substituem o político, uma nova gama de preocupações pode ser incluída no projeto de melhoria do capital, enfraquecendo-se por completo ou se transformando de modo mais radical conforme se "economiza" (BROWN, 2016, p. 21).

Isto é, a democracia é reposicionada no interior de princípios econômicos, não somente engendrando outras políticas, mas reconfigurando a própria cidadania. Alguns efeitos deste cenário merecem ser destacados como a intensificação da desigualdade, a intimidade entre o Estado e o capital e a individualização das responsabilidades. Os próprios cidadãos são interpelados a construir seus futuros, realizando investimentos em suas trajetórias. Neste cenário, a governança adquire um status de conceito privilegiado à medida em que "converteu-se na forma administrativa primária do neoliberalismo, a 
modalidade política que cria ambientes, estrutura as restrições e os incentivos e, por conseguinte, conduz o sujeito" (BROWN, 2016, p. 162). Esboça-se uma reconceitualização da democracia.

Na mesma direção, Laval e Dardot (2017) diagnosticam o caráter antidemocrático do neoliberalismo. Trata-se, em sua perspectiva, de uma "aceleração da saída da democracia", materializada em dois aspectos complementares, quais sejam: "por um lado, o poder renovado da ofensiva oligárquica contra os direitos sociais e econômicos dos cidadãos; de outro, a multiplicação dos dispositivos securitários dirigidos contra os direitos civis dos mesmos cidadãos" (p. 9). A novidade, de acordo com os pensadores franceses, é o modo como o neoliberalismo tornou-se capaz de articular-se com o conservadorismo, produzindo uma erosão do Estado de Direito e sendo capaz de abdicar de relações e princípios democráticos.

Do que se trata aqui é de levar em conta a radicalização neoliberal em toda a diversidade e complexidade de seus aspectos. Trata-se de entender de que a moda a crise multiforme que estamos vivendo, longe de ser um freio, tornouse um meio para governar. $O$ neoliberalismo não cessa, mediante os efeitos de insegurança e destruição que ele mesmo engendra, de se auto-alimentar e se autorreforçar (LAVAL; DARDOT, 2017, p. 15).

Em diálogo com Ézio Mauro, Zygmunt Bauman (2016) reforça esta hipótese do estado permanente de crise e expande este argumento para a dimensão existencial. Em suas palavras, "todos nós nos sentimos vulneráveis - individual, grave e simultaneamente, como nação ou como espécie humana" (p. 13). A condição de vulnerabilidade, exposta pelo sociólogo, desliza de forma ambivalente entre a liberdade e a segurança e manifesta-se no próprio declínio da democracia. Condição deste cenário é o enfraquecimento do Estado-Nação e a promoção de políticas imediatistas.

Em termos sociológicos, mais uma vez recorrendo a Bauman, deparamonos com o advento de uma concepção de cidadania cada vez mais individualizada, sintonizada com a "mentalidade da sociedade de consumidores" (2016, p. 32) e que implica novos sintomas para uma crise da democracia.

Tudo isso significa que hoje as instituições do Estado são concebidas, moldadas e apresentadas segundo o modelo de um sociedade de mercado e sua "cultura de tirar". Elas premiam o cidadão absorvido na busca de seus próprios interesses pessoais, o cidadão que se abstém de interferir em questões e assuntos públicos - comuns a todos - que devem ser deixados ao critério neutro das políticas profissionais (BAUMAN, 2016, p. 33). 
Tomando como ponto de partida o pressentimento de um "paradoxo da democracia" anunciado por Giddens (2000), ao longo da seção procuramos descrever as condições contemporâneas para as práticas democráticas. A partir de um quadro conceitual heterodoxo, conseguimos demarcar os modos pelos quais há um descrédito dos cidadãos acerca das formas políticas, delineandose uma economização dos processos de decisão e uma individualização das responsabilidades coletivas. O desafio que exploraremos na próxima seção diz respeito aos desdobramentos deste paradoxo da democracia para as políticas curriculares hodiernas. Como são planejadas as políticas curriculares no contexto de declínio do Estado e de individualização das pautas sociais? Como são reconfiguradas tais políticas no âmbito de uma economização da vida social e da crescente influência de movimentos neoconservadores?

\section{POLÍTICAS CURRICULARES PARA O ENSINO MÉDIO NO BRASIL: RASTROS CONCEITUAIS}

No decorrer das últimas décadas, podemos constatar um deslocamento conceitual nas políticas curriculares brasileiras para o Ensino Médio. Termos como protagonismo juvenil, direitos de aprendizagem, desenvolvimento de competências e flexibilização curricular passaram a compor a gramática das atuais políticas de currículo para as juventudes em nosso país. Inúmeros argumentos são mobilizados, desde diferentes prismas políticos, na direção de defender reformas nesta etapa da escolarização em nosso país. Ora buscando sintonia com as demandas advindas das juventudes contemporâneas, ora adequando-se aos novos contornos do mundo do trabalho, evidencia-se uma preocupação em alinhar às políticas curriculares para o Ensino Médio no Brasil a um conjunto de novos direcionamentos.

Precisamos destacar a promoção de um conjunto de novas possibilidades organizativas para esta etapa da educação básica, retomando brevemente o cenário em que se consolidou o atual processo de reforma do Ensino Médio, estabelecida a partir da Lei no 13.415 de 26 de fevereiro de 2017 (BRASIL, 2017). Por um lado, deparamo-nos com uma defesa da necessidade de reformas curriculares que atendam às demandas contemporâneas e que, com maior ou menor intensidade, requeiram outras necessidades formativas e que sejam capazes de sustentar a ideia de currículos mais flexíveis e que apostem no protagonismo juvenil e na sua necessidade de escolha. Por outro, assistimos a um conjunto de críticas que iniciaram com a promulgação da Medida Provisória que deu origem à referida legislação de forma a questionar o processo democrático em que deveriam ser construídas as políticas curriculares e aos fundamentos da proposta que se centra 
na proposição de itinerários formativos e na flexibilização curricular. Também significou um processo de precarização ou de enfraquecimento do currículo pensado para a escolarização juvenil (RAMOS; FRIGOTTO, 2016).

Bauman (2010), ao explicitar a noção de "cultura da oferta", nos ajuda a compreender o cenário de defesa da atual reforma curricular, uma vez que o Novo Ensino Médio propõe uma organização curricular "mais flexível, que contemple uma Base Nacional Comum Curricular (BNCC) e a oferta de diferentes possibilidades de escolhas aos estudantes, os itinerários formativos, com foco nas áreas de conhecimento e na formação técnica e profissional" (BRASIL, 2017). Segundo a perspectiva do sociólogo, na fase líquido-moderna em que vivemos a "cultura é feita na medida de escolha individual (voluntária ou imposta por obrigação), é destinada a servir as exigências da liberdade" (BAUMAN, 2010, p. 330). Dessa forma, esse indivíduo - jovem estudante - é o sujeito dessa cultura da oferta e recebe o direito de ser o único administrador da "política da (sua) vida". Ainda nessa direção, Mariano Enguita (2017, p.33) sinaliza que os dilemas de nosso tempo são outros, marcados por um cenário de "informação e de globalização" em que, segundo o autor, precisamos estar em diálogo com as necessidades das juventudes, destacando que mesmo os mais pobres necessitam de uma "qualificação de toda a cidadania para que estes tenham condições de competir- e contribuir- em uma economia global" (ENGUITA, 2017, p.33, tradução nossa).

Em outra direção, Ferreti e Silva (2017), Ramos e Frigotto (2016), Lima (2019), Gallian e Santos (2018) e Silva (2017), por caminhos analíticos heterogêneos, estabelecem um diagnóstico crítico da atual reforma, a qual, centrada na flexibilização curricular, apostou no desenho de itinerários formativos que possibilitariam ao jovem protagonista a escolha de seu percurso curricular. Sendo que, neste cenário, para muitos pesquisadores do campo, têm-se uma fragilização do currículo: perde-se de vista a formação integral, objetivo central de muitas políticas curriculares anteriores, e precariza-se o acesso a conhecimentos relevantes. Ferreti e Silva (2017), evidenciam o cenário de disputas em que se inscreveu a Reforma do Ensino Médio e seus objetivos acerca da escolarização juvenil.

O maior ou menor atrelamento da reforma curricular a questões de ordem pragmática, tais como a adequação a demandas econômicas e de mercado, a melhoria do desempenho dos estudantes nas avaliações em larga escala, ou, ainda, a contenção do acesso à educação superior por meio da profissionalização, entre outras, caracteriza disputas por hegemonia em torno de um projeto formativo e de sociedade, disputas que atravessam o Estado e suas instâncias decisórias no âmbito do legislativo e do executivo, bem como de seus interlocutores (FERRETI; SILVA, 2017, p. 396). 
Nas condições acima explicitadas, Ramos e Frigotto (2016) afirmam que a reforma foi estabelecida com base na "dissociação entre ensinar e educar e na condução de um processo de ensino com base na fragmentação e no pragmatismo" (p.37). Destacam ainda o caráter autoritário de sua implementação, assim como a crítica a precariedade causada pela anunciada escolha dos jovens, de forma que esta proposta pode produzir desigualdade no acesso ao conhecimento.

Nesta esteira, Lima (2019), escrevendo a partir do contexto português, alerta-nos sobre a impregnação empresarial das escolas, que faz parte da cultura do novo capitalismo e que compõe uma nova gramática que envolve as atuais reformas curriculares contemporâneas. $\mathrm{O}$ autor nos apresenta elementos que permitem uma reflexão ampliada sobre os paradoxos da democracia que emergem dessa racionalidade.

\begin{abstract}
Embora apelando à adesão voluntária e engajada a novos processos de intensificação do trabalho discente e docente, as políticas educacionais e as organizações escolares tendem a exercer processos de liderança fortes, a criar instrumentos de controle e de disciplinação, a usar processos sofisticados de condicionamento por meio de uma organização hipermecanicista que, assente no mundo digital e em processos de vigilância individualizada, se apresenta, paradoxalmente, sob o discurso da descentralização e da autonomia, da flexibilidade, da participação dos interessados e da pós- burocracia (LIMA, 2019, p. 14)
\end{abstract}

Ao apresentar seu diagnóstico sobre as políticas curriculares, Silva (2014, p.147) já sinalizava para a existência de dispositivos de "customização curricular", os quais centravam-se na possibilidade do estudante constituir seu percurso formativo, pautado em características como a flexibilidade, a criatividade e a personalização. Nessa direção, o autor destaca que, em meio as condições do capitalismo contemporâneo, "emergem um conjunto de racionalidades governamentais que regulam e orientam as pautas curriculares através da articulação entre individualização e responsabilização" (SILVA, 2017, p.700). Nesta direção, Galian e Santos (2018) também apresentam um diagnóstico relevante ao demonstrar que a Reforma do Ensino Médio, a BNCC, a projeto Escola Sem Partido e a PEC 241/55, que estabelece um teto para os gastos públicos, têm em comum fazerem parte de um cenário em que se traz à tona "a tradição de desigualdades sociais, de concentração de renda, privilégios, oportunidades" (p.166) e que faz frente a uma situação de "amadurecimento da democracia" a qual tentava-se construir até então. Nessa mesma direção, Lima e Hypólito (2019, p.12) destacam que "uma análise dos temas incluídos e excluídos da BNCC corrobora o entendimento de que há um crescimento das ideias neoconservadoras em relação à educação brasileira". 
Dessa maneira, em outro estudo, ao analisarem os objetivos da constituição da BNCC, Galian e Silva (2019) mapeiam a "vinculação estreita entre a qualidade da educação e as aprendizagens desenvolvidas pelos estudantes com aquilo que eles devem aprender na escola" (p.519). De acordo com os autores, o documento foi construído com vistas a garantir a qualidade da educação já que estabelece um conjunto de aprendizagens a que todos os estudantes brasileiros devem ter acesso, e que designar o que todos os estudantes devem aprender "é parte fundamental da construção de garantia de patamares comuns de aprendizagem, por meio da melhoria do ensino" (p.521).

Em consonância com que se propõe a atual proposta do Novo Ensino Médio, a BNCC para a última etapa da educação básica, propõe-se ao desenvolvimento das competências gerais da educação básica e das competências específicas das áreas do conhecimento, organizadas a partir de itinerários formativos que "devem ser reconhecidos como estratégicos para a flexibilização da organização curricular do Ensino Médio, possibilitando opções de escolha aos estudantes" sendo que a flexibilidade deve ser tomada como princípio obrigatório pelos sistemas e escolas de todo o País" (BRASIL, 2017, p.470).

Alvo de críticas, discussões e controvérsias, a Base Nacional Comum Curricular também é vista como problemática por estudiosos do currículo em inúmeros outros aspectos: a possibilidade de reduzir a educação ao ensino ao tentar fixar ou centralizar concepções de currículo (MACEDO, 2014; CUNHA; 2015); fazer parte de um engendramento de lógicas neoliberais na educação (FERRETI; SILVA, 2017; LIMA , 2019); deslocamento da lógica dos conhecimentos para a lógica das competências (GALIAN; SANTOS, 2018).

Como buscamos evidenciar ao longo desta seção, as políticas curriculares para a escolarização juvenil na contemporaneidade podem ser situadas em campo controverso, permeado por inúmeras ambivalências e contradições que precisam ser examinadas. Uma dessas ambivalências, que ampliaremos na próxima parte deste estudo, diz respeito à reconfiguração da gramática política em torno das questões do direito à educação e da qualidade. $\mathrm{O}$ que pode ser dito sobre a tentativa de fixar um conjunto de competências, propostas na BNCC, que garantam o direito de acesso ao conhecimento e um padrão mínimo de qualidade? Como analisar os modos pelos quais o Novo Ensino Médio apresenta uma face democrática ao possibilitar a escolha dos itinerários pelos estudantes? Trata-se de uma gramática imersa em múltiplas críticas e interpretações divergentes, as quais rastreamos brevemente nesta seção. Na sequência do texto, interessa-nos problematizar as questões do direito à educação e da qualidade e compreendê-las no cenário de um paradoxo da democracia, cartografando ressonâncias para a escolarização juvenil brasileira. 


\section{ESCOLARIZAÇÃO, JUVENTUDE E O \\ PARADOXO DA DEMOCRACIA}

No decorrer das últimas duas décadas, a literatura educacional crítica que foi publicada no Brasil atribuiu uma evidência significativa às questões relacionadas ao direito e à qualidade educativos. A literatura que abordaremos nesta seção, em caráter exploratório, favorece com que possamos descrever um reposicionamento destas questões. A emergência da noção de "direitos de aprendizagem”, materializada na Base Nacional Comum Curricular, configura-se como um exemplar analítico privilegiado dos modos pelos quais as demandas individuais foram ingressando neste debate. Todavia, neste momento, buscaremos produzir uma retomada do debate sobre esta questão, rastreando suas perspectivas e possibilidades para, ao final, indicar seus desdobramentos para as articulações entre escolarização, juventude e democracia.

Quando analisamos as implicações educacionais dos paradoxos da democracia delineados por Giddens, uma das questões que merece nossa atenção refere-se ao direito à educação e as suas variadas formas de garantia política. Esta questão adquire pertinência e atualidade no contexto brasileiro (e latinoamericano) em que ainda não conseguimos universalizar a proteção social e as inúmeras formas de garantia das liberdades individuais. Pesquisadores como Boto (2005), Goergen (2013) e Gentili (2009), de perspectivas teóricas diversificadas, auxiliam-nos a conceituar e a contextualizar o debate acerca do direito à educação em nosso país.

Em termos conceituais, Carlota Boto (2005) argumenta que tal como ocorre com os direitos humanos, o direito à educação poderia ser explicado por meio de três gerações. Em uma primeira geração, o ensino passa a ser reconhecido como um "direito público", a ser estendido a toda a população por meio da democratização do acesso. Posteriormente, em uma segunda geração, a educação como um direito abrange também questões de qualidade na oferta. E, em uma terceira geração, passa a abranger as especificidades de variados segmentos da população.

O direito da educação será consagrado quando a escola adquirir padrões curriculares e orientações políticas que asseguram algum patamar de inversão de prioridades, mediante atendimento que contemple - à guisa de justiça distributiva - grupos sociais reconhecidamente com maior dificuldade para participar desse direito subjetivo universal - que é a escola pública, gratuita, obrigatória e laica (BOTO, 2005, p. 779). 
A emergência desta terceira geração de direitos, ainda que se inscreva no âmbito da igualdade - sob uma perspectiva universalista -, passa a abranger o debate atinente à diversidade e à multiplicidade de formas identitárias que a acompanham. De acordo com Boto (2005), o currículo seria um dos espaços em que esta articulação entre igualdade e diversidade poderia ser visibilizada. Ou ainda, "romper com algumas amarras simbólicas do conhecimento escolar exigiria um esforço voltado não mais agora para a direção exclusiva da igualdade, ainda que com qualidade, mas, substancialmente, para projetar, acatar e conviver com as diferenças" (p. 790).

O reconhecimento coletivo dos direitos implica, por um lado, a valorização das individualidades e, por outro, a percepção da educação como "direito de cidadania e responsabilidade do Estado" (GOERGEN, 2013). Conforme Pedro Goergen (2013), sob um prisma filosófico, precisamos retomar o debate acerca das modalidades de atuação do Estado para garantir a promoção de educação de qualidade a toda a população. Após uma breve incursão histórica pelo pensamento político moderno, o filósofo expõe que naquele momento havia muita clareza quanto à necessidade "de uma instância superior como garantia de liberdade e convivência pacífica entre os seres humanos, independentemente do nome que lhe fosse dados e dos argumentos usados para justificá-la" (p. 729). Ou seja, destacava-se a necessidade de encontrar equilibrio entre os interesses individuais e públicos.

Seja na perspectiva do liberalismo, seja pelo caminho do comunitarismo, esboça-se um consenso de que a educação é uma "condição inalienável do direito à cidadania" (p. 729). Entende-se por cidadania, conforme Goergen (2013), a "capacidade de intervir tanto nos espaços privados da ordem econômica, quanto nos assuntos públicos de ordem política” (p. 732). A educação ocupa um papel privilegiado no que tange à formação cidadã.

Apesar de suas inúmeras deficiências, limites e problemas, ela continua sendo o principal recurso de formação para a cidadania com tudo o que isso implica. É, portanto, lógico que o exercício da cidadania, certamente o principal direito do ser humano como ser social, pressupõe o acesso à educação. Disso se depreende que a sociedade democrática, em seu sentido pleno, é aquela em que todos os seus integrantes têm acesso à educação, e uma educação de qualidade tal que lhe dê condições para o exercício pleno da cidadania (GOERGEN, 2013, p. 732).

Por meio da intensificação da gramática do neoliberalismo, ocorre um declínio da atuação do Estado no âmbito da garantia dos direitos e da promoção da cidadania, atingindo diretamente o campo educacional (BOTO, 2005; GOERGEN, 2013). Segundo Gentili (2009), no contexto latino-americano, 
engendram-se novas dinâmicas de exclusão social, materializadas na pobreza e na desigualdade estruturais, na diferenciação dos sistemas de ensino e por uma cultura política marcada pela concorrência.

Na acepção do autor, em perspectiva crítica, no contexto latino-americano poderíamos falar em uma "exclusão includente" (GENTILI, 2013), em que o processo de exclusão tende a assumir novas fisionomias.

\begin{abstract}
O conceito de exclusão includente pretende chamar a atenção sobre a necessidade de pensar o conjunto de dimensões que estão presentes em todo o processo de discriminação, alertando para o fato de que, a partir desta multidimensionalidade, a necessária construção de processos sociais de inclusão (associados à realização efetiva dos direitos humanos e cidadãos e à consolidação de relações igualitárias sobre as quais se constroem as bases institucionais e culturais de uma democracia substantiva) sempre depende de um conjunto de decisões políticas orientadas a reverter as múltiplas causas da exclusão, e não somente algumas delas, particularmente as mais visíveis (GENTILI, 2013, p. 1061).
\end{abstract}

Outra dimensão evidenciada contemporaneamente encontra-se nos debates estabelecidos acerca da questão da qualidade da educação ofertada no âmbito de sua democratização. De acordo com Cury (2014), no contexto brasileiro, ao longo das últimas décadas conseguimos delinear a qualidade da educação como um direito, preservado em variados documentos de caráter normativo. A qualidade, enquanto um atributo distintivo, em nossa linguagem cotidiana remetese a um "atributo ou predicado virtuoso pelo qual esse sujeito, bem ou serviço se distingue de outros semelhantes considerados ordinários" (CURY, 2014, p. 1054).

Em nosso ordenamento jurídico, a qualidade é recorrentemente defendida desde a Constituição Federal de 1988 que já apregoava - em seu artigo 206 - a definição de "padrões mínimos de qualidade". Outros documentos posteriores, cada um a sua maneira, levavam adiante este princípio como na Lei de Diretrizes e Bases da Educação Nacional e nos Planos Nacionais de Educação. O pleno desenvolvimento da pessoa, o preparo para o exercício da cidadania e a preparação para o trabalho, enquanto pontos de partida de caráter universal, foram mobilizados na composição de uma agenda educacional com foco na qualidade. Conforme os estudos de Cury (2008), a própria concepção de uma educação básica - enquanto direito de todos - configura-se como um importante avanço conceitual na direção da democratização.

Em sua perspectiva, o contexto pós-1988 favoreceu a composição de uma "nova esfera pública democrática", capaz de novos conceitos derivados de novas expectativas sociais. 
É nesse momento de ruptura com a ordem existente que a CF a atravessa dandolhes novos contornos organizacionais e chamando essa mesma ordem para uma cidadania aberta a todos. Assim, para fazê-la direito de todos, era imprescindível que houvesse algo de comum ou universal. É dessa inspiração, declarada e garantida na Constituição, que a educação escolar é proclamada direito. Dela se espera a abertura, além de si, para outras dimensões da cidadania e da petição de novos direitos (CURY, 2008, p. 297).

A construção da escola como direito universal materializava um conjunto de demandas ao Estado erigidas nas décadas precedentes. Esperava-se da escola a difusão de conhecimentos, o combate às desigualdades e à intolerância, e a defesa de procedimentos democráticos. Todavia, ao mesmo tempo em que se garante institucionalmente o acesso universal a uma educação de qualidade, as novas configurações da cidadania passam a reivindicar a diferença como um direito. Sob um prisma universalista, Cury (2008) defenderá que "o reconhecimento das diferenças nesse momento da escolaridade é factível com o reconhecimento da igualdade" (p. 301).

Este tensionamento entre a garantia universal de direitos e o reconhecimento das diferenças delineará os debates no âmbito das políticas públicas (LAVALLE, 2003), de uma forma ampla, e das políticas curriculares (ARROYO, 2011), especificamente. Outros contornos para a cidadania são traçados e ampliaremos este debate neste momento. De acordo com Lavalle (2003), por meio do binômio igualdade/diferença, a cidadania moderna tem sido questionada em suas "plausibilidade política" e "viabilidade simbólica". Isto é, a cidadania mereceria ser interpretada em suas ambivalências.

A cidadania torna-se vetor de integração social e, ao mesmo tempo, precisa atender as pautas identitárias.

Especificamente, no que diz respeito à igualdade, cabe lembrar que o quid reside no fato de a cidadania ter introduzido distinção dupla, de inclusão e exclusão: primeiro, expandiu o terreno da igualdade garantido pela lei, isto é, determinou áreas relevantes da vida social nas quais deviam primar condições de acesso, participação ou usufruto semelhante para os segmentos sociais investidos de status cidadão; segundo, a consagração dessas áreas - da herança social a ser compartilhada como pressuposto de uma vida civilizada - simultaneamente desautoriza a legitimidade de qualquer demanda que escape de suas fronteiras (LAVALLE, 2003, p. 82-83).

Em termos de políticas curriculares, acompanhando a apreciação de Arroyo (2011), seria pertinente uma retomada do debate sobre a construção da desigualdade, na interface com as questões da igualdade e das diferenças. De acordo com o autor, "as desigualdades escolares são reduzidas a capacidades desiguais dos alunos, responsabilizando-os pelas desigualdades escolares” (p. 
84). A atual ênfase em avaliações rigorosas, associada aos elevados índices de reprovação e abandono escolar, conduzem a um processo de responsabilização dos próprios estudantes sobre seus sucessos e fracassos.

Mais uma vez recorrendo a Arroyo, "essa redução das desigualdades escolares aos alunos se acentua ao estarem chegando às escolas os (as) filhos (as) dos coletivos populares, os mais desiguais" (2011, p. 85). Para tanto, uma alternativa evidenciada pelo autor diz respeito ao necessário deslocamento da análise para o âmbito das escolas, das redes de ensino e das próprias políticas educacionais. Valeria a pena interrogar: “Uma das funções das análises de políticas não poderia ser explicitar essas perversas conexões entre qualidade das escolas, dos lugares, até da nação e a má 'qualidade' dos coletivos que os frequentam?" (ARROYO, 2011, p. 86).

Deslocando o olhar para a literatura internacional, sobre esta questão e ampliando o escopo desta argumentação, junto a Dubet (2008) seria pertinente refletir sobre a produção das desigualdades e a construção da justiça na escola. No contexto de intensa democratização da escolarização na França, o sociólogo diagnostica que o deslocamento da igualdade de acesso para a igualdade de oportunidades engendrou novos sentimentos de injustiça. Os tensionamentos entre a igualdade na oferta e as formas de discriminação positiva perfazem os debates entre "os que desejam renunciar ao colégio único e aqueles que querem instalar um colégio construído sobre uma cultura comum, ou seja, sobre um conjunto de conhecimentos e competências exigíveis a todos" (DUBET, 2008, p. 387).

Conforme a argumentação de Dubet (2008), as preocupações com a igualdade de oportunidades engendram novas modalidades de injustiça. A mais denunciada pelos estudantes franceses seria o "desprezo", uma vez que "tudo se passa como se os vencedores e vencidos tivessem interiorizado a escala das dignidades escolares fixando o mecanismo de orientação para os fracassos e as lacunas mais que pelos projetos e as capacidades" (DUBET, 2008, p. 389). Os efeitos da democratização, sob essa perspectiva, a despeito das formas de ampliação do acesso, despertaram fortes decepções.

Do ponto de vista democrático, toda a dificuldade vem do fato de que os vencedores têm uma espécie de monopólio da palavra e da legitimidade, enquanto os perdedores se sentem inválidos e não podem nem querem empenhar a palavra. Esses desequilíbrios profundos acentuam as dificuldades dos menos favorecidos e a exclusão dos excluídos no seio de um modelo no qual continuamos convencidos de que as desigualdades produzidas pela escola continua, no fundo, profundamente justas. Assim, o caminho entre a crítica dos sociólogos e a crítica social fica mais longo e mais tortuoso do que poderíamos acreditar (DUBET, 2008, p. 391). 
Ao analisar cenários de crise e de reprodução de desigualdades, Dussel ( 2003, p.23) nos encoraja a não nos ajustarmos à realidade e nos desafia a "pensarmos formas de intervenção" que produzam as mudanças no cenário em que nos encontramos, por meio de um "atuar politicamente". Atuar politicamente, apostando em um processo de "repolitizar a crise e repolitizar a escola" (DUSSEL, 2003, p.25). Ao pensarmos os parodoxos da democracia em nossos tempos, a aposta em processos de repolitização apresenta-se como possibilidade de democratização, de confiança nos sujeitos e nas suas capacidades de contribuição política, em um cenário em que as dimensões democráticas encontram-se ameaçadas. Ainda que apregoando a qualidade e o direito à educação, os atuais direcionamentos para o Ensino Médio inscrevem-se em um campo bastante controverso, como sistematizaremos a seguir.

\section{CONSIDERAÇÕES FINAIS}

No decorrer do presente estudo buscamos explicitar os modos pelos quais as políticas curriculares para o ensino médio, atualmente implementadas, estão imersas em um cenário que Giddens (2000) denominou como 'paradoxo da democracia'. Ao tomarmos como elementos centrais desta análise a questão da qualidade da educação e os direitos de aprendizagem podemos visualizar os engendramentos apresentados pelo sociólogo contemporâneo. Se, por um lado, as atuais políticas buscam estabelecer um padrão de qualidade que define o que se deve aprender na escola, como garantia de direitos e dessa forma como sinal de democratização desses processos; por outro, vemos nas políticas contemporâneas a emergência de um discurso cada vez mais individualizante e meritocrático, em que o sucesso ou fracasso são considerados responsabilidade de cada sujeito, seja ele estudante ou docente.

$\mathrm{Na}$ primeira seção revisamos as teorizações sociais contemporâneas, visando buscar os rastros do paradoxo da democracia, derivado da intuição analítica manifestada por Giddens (2000). Na sequência examinamos as ressonâncias deste argumento no âmbito das recentes reformulações curriculares implementadas no contexto brasileiro, especialmente a partir da Lei n. 13.415/2017 e da Base Nacional Comum Curricular. Na terceira e última seção, atribuímos ênfase aos conceitos de qualidade e direito à educação no Brasil, revisando a ampla produção científica sobre a questão nas últimas duas décadas. Os efeitos do referido paradoxo da democracia, no que tange à escolarização juvenil, remetem-nos a problematizar os modos pelos quais a garantia do direito à uma educação de qualidade foi - gradativamente - migrando para a esfera individual. Tal migração torna-se tangível a partir do advento da noção de direitos de aprendizagem. As 
tensões entre o universal e o particular, ou ainda entre os imperativos da escola para todos e das aprendizagens individuais, adquirem novos contornos neste início de século XXI.

$\mathrm{Na}$ leitura que estamos desenvolvendo, ainda em caráter preliminar, compreendemos que este cenário seja favorável para a composição de uma nova agenda de direitos para a escolarização juvenil, assentada em mecanismos de governança escolar democrática (TORT; COLLET, 2016). A defesa da escuta e da negociação permanente com os estudantes - assentada em formas curriculares marcadas pela protagonismo juvenil e pela construção de projetos de vida - favorece a ampliação de nossa interpretação da escola democrática na atualidade. Ao mesmo tempo, a preocupação com as demandas individuais e processos formativos baseados na customização curricular (SILVA, 2019) precisa ser cotejada com os marcos de uma formação humana em comum. A noção de direitos de aprendizagem, em sua condição de ambivalência, precisa ser examinada desde uma perspectiva mais alargada, o que realizaremos em estudos futuros.

Ao estabelecer esse diagnóstico crítico sobre as políticas de escolarização juvenil e os paradoxos da democracia, apostamos na necessidade de revitalizar os processos democráticos investindo na participação ativa e efetiva das juventudes nos processos de constituição de um currículo escolar em consonância com as necessidades de nossos tempos, para que estes possam desenvolver graus de confiança nas instituições.

\section{REFERÊNCIAS}

APPLE, Michael. Produzindo diferença: neoliberalismo, neoconservadorismo e a política de reforma educacional. Linhas Críticas, v. 21, n. 46, p. 606-644, 2016.

ARROYO, Miguel. Políticas educacionais, igualdade e diferença. Revista Brasileira de Política e Administração da Educação, v. 27, n. 1, p. 83-94, 2011.

BALL, Stephen. Gobernanza neoliberal y democracia patológica. In: COLLET, Jordi; TORT, Antoni. (Orgs.). La gobernanza escolar democrática. Madrid: Morata, 2016, p. 23-40.

BAUMAN, Zygmunt. Babel: entre a incerteza e a esperança. Rio de Janeiro: Zahar, 2016.

BAUMAN, Zygmunt. Capitalismo parasitário. Rio de Janeiro: Zahar, 2010. 
BOTO, Carlota. A educação como direito humano de três gerações: identidades e universalismos. Educação \& Sociedade, v. 26, n. 92, p. 777-798, 2005.

BRASIL, Lei $\mathrm{n}^{\circ}$ 13.415, de 16 de fevereiro de 2017. Altera as Leis $\mathrm{n}^{\circ}$ 9.394, de 20 de dezembro de 1996, que estabelece as diretrizes e bases da educação nacional, e 11.494, de 20 de junho 2007, que regulamenta o Fundo de Manutenção e Desenvolvimento da Educação Básica e de Valorização dos Profissionais da Educação, a Consolidação das Leis do Trabalho - CLT, aprovada pelo DecretoLei $\mathrm{n}^{\circ} 5.452$, de $1^{\circ}$ de maio de 1943, e o Decreto-Lei $\mathrm{n}^{\circ} 236$, de 28 de fevereiro de 1967; revoga a Lei n ${ }^{\circ} 11.161$, de 5 de agosto de 2005; e institui a Política de Fomento à Implementação de Escolas de Ensino Médio em Tempo Integral. Diário Oficial da União: seção 1, Brasília, DF, n.35, p.1-3, 17 fev. 2017.

BRASIL. Ministério da Educação. Base Nacional Comum Curricular. Educação é a Base. Ensino Médio. Brasília: MEC, 2018.

BROWN, Wendy. El pueblo sin atributos: la secreta revolución del neoliberalismo. Barcelona: Malpaso, 2016.

COLLET, Jordi; TORT, Antoni (Orgs.). La gobernanza escolar democrática. Madrid: Morata, 2016.

CONNELL, Robert William. Escuelas y justicia social. Madrid: Ediciones Morata, 1997.

CUNHA, Érika Virgílio. Cultura, contexto e a impossibilidade de uma unidade essencial para o currículo. Currículo sem Fronteiras, Rio de Janeiro, v. 15, n. 3 , p. 575 587, set./dez. 2015.

CURY, Carlos Roberto Jamil. A qualidade da educação brasileira como direito. Educação \& Sociedade, v. 35, n.129, p. 1053-1066, 2014.

CURY, Carlos Roberto Jamil. A educação básica como direito. Cadernos de Pesquisa, v. 38, n. 134, p. 293-303, 2008.

DUBET, François. Democratização escolar e justiça da escola. Educação UFSM, v. 33, n. 3, p. 381-394, 2008. 
DUSSEL, Inés; FINOCCHIO, Silva (Coords.). Enseñar hoy: una introducción a la educación en tiempos de crisis. Buenos Aires: Fondo de Cultura Económica, 2003.

ENGUITA, Mariano Fernández. La dinâmica del capital humano y los interfaces del nuevo entorno. In: SACRISTÁN, José Gimeno(Comp.). Los contenidos, una reflexión necessária. $1^{a}$ ed. São Paulo: Cortez, 2017, p. 27-33.

FERRETI, Celso João; SILVA, Monica Ribeiro da. Reforma do Ensino Médio no contexto da Medida Provisória n. 746/2016: Estado, currículo e disputas por hegemonia. Educação e Sociedade, Campinas, v. 38, n. 139, p. 385-404, abr./ jun. 2017.

GALIAN, Claudia Valentina Assumpção; SANTOS, Vinício. Concepções em disputa nos debates sobre a BNCC: educação, escola, professor e conhecimento. In: GODOY, Elenilton; SILVA, Marcio; SANTOS, Vinício (Orgs.). Currículos de matemática em debate. São Paulo: Editora Livraria da Física, 2018.

GALIAN, Claudia Valentina Assumpção; SILVA, Roberto Rafael Dias da. Apontamentos para uma avaliação de currículos no Brasil: a BNCC em questão. Estudos em Avaliação Educacional, São Paulo, v. 30, n. 74, p. 508-535, maio/ ago. 2019 .

GENTILI, Pablo. O direito à educação e as dinâmicas de exclusão na América Latina. Educação \& Sociedade, v. 30, n. 109, p. 1059-1079, 2009.

GIDDENS, Anthony. Mundo em descontrole. Rio de Janeiro: Record, 2000.

GOERGEN, Pedro. A educação como direito de cidadania e responsabilidade do Estado. Educação \& Sociedade, v. 34, n. 124, p. 723-742, 2013.

LAVAL, Christian; DARDOT, Pierre. La pesadilla que no acaba nunca. Barcelona: Gedisa, 2017.

LAVALLE, Adrian. Cidadania, igualdade e diferença. Lua Nova, n. 59, p. 75 93, 2003. 
LIMA, Ilana Gomes de; HYPOLITO, Álvaro Moreira. A expansão do neoconservadorismo na educação brasileira. Educação e Pesquisa, São Paulo, v.45, e190901,2019, p. 115.

LIMA, Licínio. Uma pedagogia contra o outro? Competitividade e emulação. Educação e Sociedade, v.40, e0218952, p. 1-18, 2019.

LIMA, Licínio. Por que é tão difícil democratizar a gestão da escola pública? Educar em Revista, v. 34, n. 68, p. 15-28, 2018

MACEDO, Elizabeth. Base Nacional Curricular Comum: Novas formas de sociabilidade produzindo sentidos para educação. Revista e-Curriculum, São Paulo, v. 12, n. 03, p. 1530-1555, out./dez. 2014.

SANTOS, Boaventura de Sousa. A Cruel Pedagogia do Vírus. Coimbra: Edições Almedina, S.A, 2020.

SENNET, Richard. A cultura do novo capitalismo. 7. ed. Rio de Janeiro: Record, 2019.

SILVA, Roberto Rafael Dias da. Políticas de constituição do conhecimento escolar para o Ensino Médio no Rio Grande do Sul: uma analítica de currículo. Educação em Revista, v. 30, n. 1, p.127-156, 2014.

SILVA, Roberto Rafael Dias da. Emocionalização, algoritmização e personalização dos itinerários formativos: como operam os dispositivos de customização curricular? Currículo sem Fronteiras, 2017, v. 17, p. 699-717.

RAMOS, Marise Nogueira; FRIGOTTO, Gaudêncio: Medida Provisória 746/2016: a contra-reforma do Ensino Médio do golpe de estado de 31 de agosto de 2016. Revista HISTEDBR On-line, Campinas, nº 70, p. 30-48, dez. 2016.

VIÑAO, Antonio. El modelo neoconservador de gobernanza escolar: principios, estrategias y consecuencias en España. In: COLLET, Jordi; TORT, Antoni. (Orgs.). La gobernanza escolar democrática. Madrid: Morata, 2016, p.41-64. 


\section{Roberto Rafael dias da Silva}

Professor do Programa de Pós-Graduação em Educação da Universidade do Vale do Rio dos Sinos - UnisinosBolsista de Produtividade em Pesquisa do CNPq. E-mail: robertoddsilva@yahoo.com.br

\section{Luthiane Miszak Valença de Oliveira}

Doutoranda em Educação pela Universidade do Vale do Rio dos Sinos. E-mail: luthimv@hotmail.com

Recebido em: 11/09/2020

Aprovado em: 28/05/2021 